\title{
Polishing Technique to Identify Particles in Polygranular Graphite
}

\author{
R.M. Paul,* J.E. Morral,**
}

* Ph.D. Candidate, Department of Materials Science and Engineering, The Ohio State University, Columbus, $\mathrm{OH}, 43210$

** Professor, Department of Materials Science and Engineering, The Ohio State University, Columbus, $\mathrm{OH}, 43210$

Polygranular graphite is a type of composite material. It is primarily composed of coke particles, fines and a binder of coal-tar pitch that have been graphitized by heat treatment. Its properties, e.g. density, can be controlled by tailoring the particle size and the processing steps [1\& 2]. The microstructural features of a graphite material, however, are not easily revealed using standard metallographic techniques. Specifically, there is often poor contrast between the particles and binder phase after polishing when viewed with a metallograph (Figure 1). The grayscale histogram corresponding to this micrograph cannot be thresholded to distinguish between the particles and binder. The objective of this work was to develop a final polishing step that would enhance the apparent contrast. This would enable the image to be thresholded and quantitative image analysis to be performed, for example to measure the size distribution or volume fraction of particles.

The metallographic procedures were performed on samples of G-90 graphite, a high-density grade of graphite manufactured by Pyrotek Metaullics. It has an apparent density of $1.9 \mathrm{~g} / \mathrm{cm}^{3}$ and a maximum particle size of 200 microns [3]. Samples were vacuum-mounted in epoxy resin, ground and polished to a one micron finish. As a final step, samples were polished with residual graphite on the polishing cloth, which presumably filled in the binder phase around the particles. The result of the new final polishing step is shown in Figure 2. The improved contrast between the phases allowed the image to be thresholded to distinguish between the particles, binder and porosity. Image analysis was performed using the new micrographs, and the volume fraction and size distribution of the particles was measured.

\section{References}

[1] P. Morgan, Carbon Fibers and their Composites, Taylor \& Francis, Boca Raton, 2005.

[2] H.O. Pierson, Handbook of Carbon, Graphite, Diamond and Fullerenes: Properties, Processing, and Applications, Noyes, New Jersey, 1993.

[3] Pyrotek Metaullics, Specialty Graphite Rods and Tubes, http://www.pyrotek.info/metaullics/ (accessed February 1, 2010).

[4] This research was supported by the U.S. Office of Naval Research under contract N00014-041-0683 and a Graduate Fellowship from the National Science Foundation GK-12 Program. The authors gratefully acknowledge Mr. Michael Gilbert at GrafTech in Parma, OH for advice on graphite microscopy. 

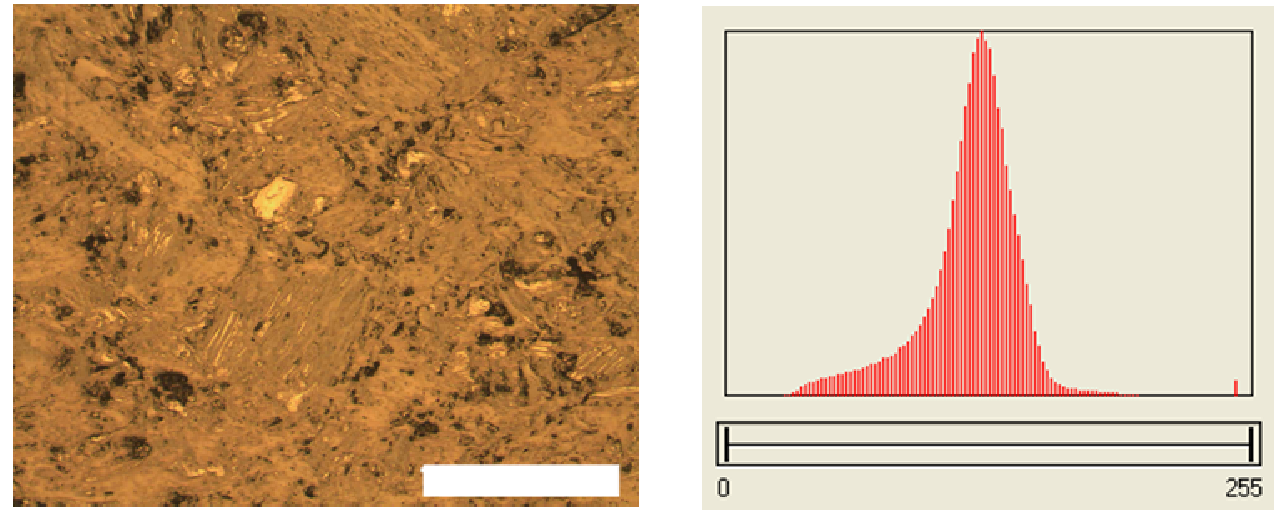

FIG. 1. Micrograph and grayscale histogram of polished graphite using the old method. The scale bar is 200 microns.
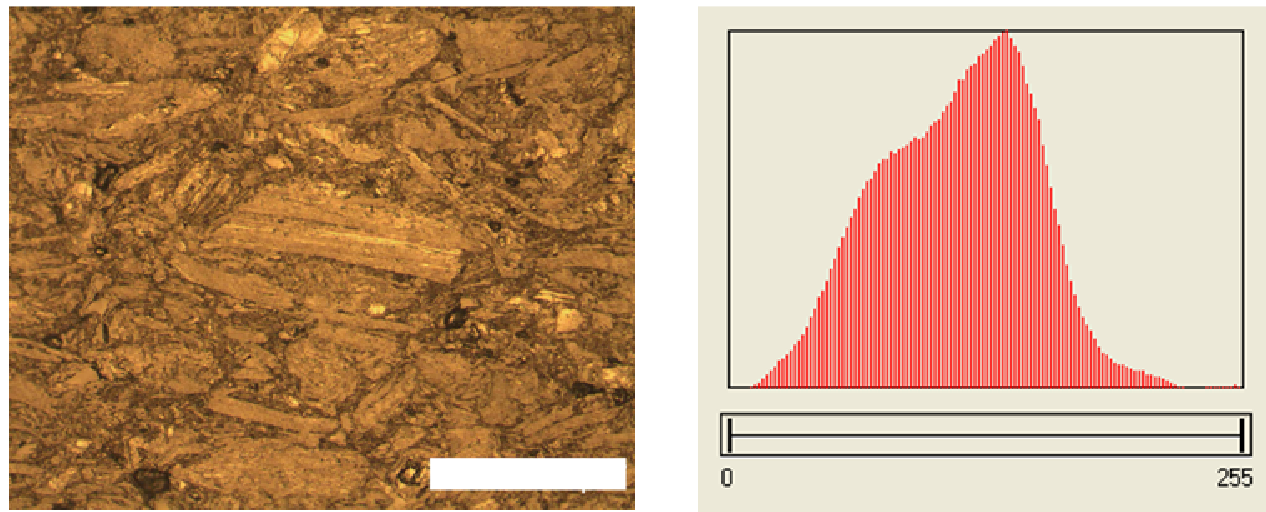

FIG. 2. Micrograph and grayscale histogram of polished graphite using the new method. The scale bar is 200 microns. 